\title{
Surpresas da Condensação de Michael *
}

\section{Introdução}

A condensação de Michael, descoberta há mais de cem anos, continua a apresentar alguns aspectos aparentemente incompreensíveis, não obstante o acumular de teorias, verificações e postulados a que tem dado origem.

Inicialmente introduzida como se representa na Figura 1, [1]

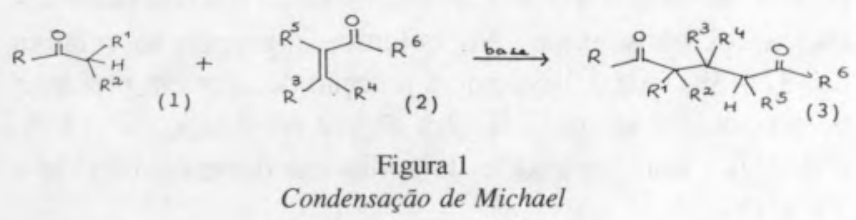

desde cedo se constatou que o composto 1,5-dicarbonílico formado pode, nas mesmas condições que lhe deram origem, ser a base de um eficiente processo de síntese de compostos cíclicos - anelação de Robinson [2,3], Figura 2.

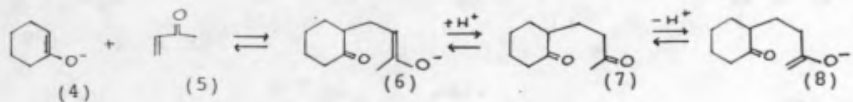

$$
\begin{aligned}
& \rightleftarrows \mathrm{OHO}_{\mathrm{OH}(9)} \stackrel{-\mathrm{HO}_{\mathrm{O}}}{\rightarrow} \mathrm{O}_{(10)} \\
& \text { Figura } 2 \\
& \text { Anelação de Robinson }
\end{aligned}
$$

No entanto, a própria condensação de Michael pode originar directamente produtos cíclicos:

i) Se o dador e o aceitador de Michael estiverem incluídos na mesma molécula, (condensação de Michael intramolecular); ii) Se se derem duas condensações de Michael seguidas, (dupla condensação ou condensação de Michael sequencial). Para todos os casos é possível apontar alguns exemplos cujos resultados se podem considerar inesperados; todavia, considerações de ordem estereoquímica, de análise conformacional do estado de transição, do estudo cinético e dos efeitos estereoelectrónicos permitem dar justificação racional a muitos dos factos apresentados.

\section{Anelação de Robinson}

Em termos gerais, a ciclização aldólica posterior a uma condensação de Michael pode dar-se em dois sentidos, de acordo com a cetona que preferencialmente enoliza, Figura 3,

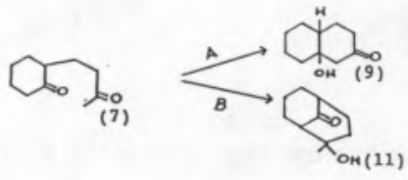

Figura 3

Ciclizaçâo aldólica

e de facto em muitas das condições usadas referidas na literatura obtiveram-se misturas dos dois tipos de ciclização. Repare-se na mudança de estereoquímica que se verifica nas ciclizações aldólicas dos aductos de Michael da ciclohexanona e da 2-metil-ciclohexanona [4], Figura 4.

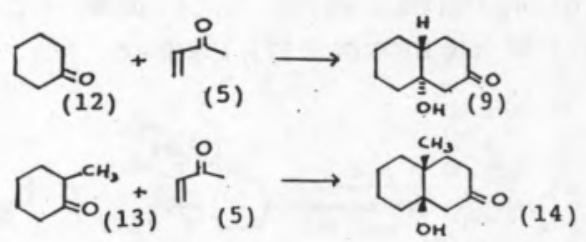

Figura 4

Cetóis da ciclohexanona e da 2-metil-ciclohexanona

Nestes casos, o efeito cinético devido à presença do substituinte na posição $\alpha$ em relação à cetona no aducto de Michael intermediário é determinante, uma vez que se forma o isómero menos estável e mais impedido, cis. Na ausência de impedimento estereoquímico, forma-se o isómero trans [5], Figura 5.

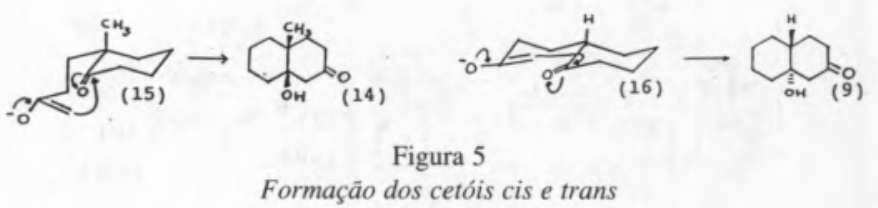

Não deixa de ser também curiosa a formação exclusiva do isómero (18) na ciclização aldólica do aducto de Michael (17) [6]; no entanto, o tratamento ligeiro com base do isómero formado, (18), origina um seu epímero, (19), Figura 6 ,

\footnotetext{
assistente no Departamento de Química da Faculdade de Ciências da Universidade de Lisboa.

* Este artigo constitui um resumo da prova de capacidade científica apresentada para a passagem à categoria de Assistente segundo o artigo $58 .^{\circ}$ do Estatuto da Carreira Docente Universitária.
} 


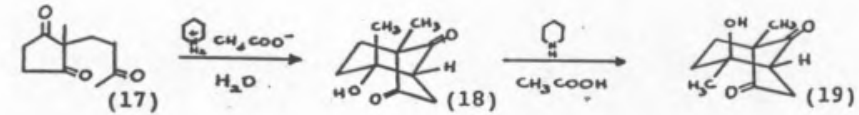

Figura 6

Ciclizaçāo aldólica do aducto (17)

Uma explicação plausível é a que se baseia na análise dos estados de transição conducentes a cada um dos epímeros, Figura 7 ,

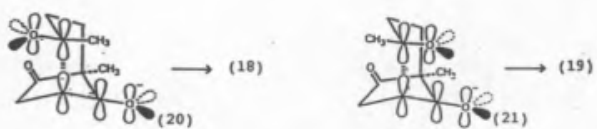

Figura 7

Estados de transiçâo que originam (18) e (19)

que mostra que (20) é mais estabilizado por motivos electrónicos do que (21) [5] - há uma relação antiperiplanar entre a dupla ligação enólica atacante e o grupo carbonilo atacado em (20).

A ciclização sob pressão elevada, (15 000 atmosferas), de $\beta$-dicetonas e $\beta$-cetoésteres com aceitadores possuindo substituintes na posição $\beta$ conduziu quase exclusivamente à formação de cetóis tipo $B$, (verFigura 3), só se detec-tando a formação maioritária de um cetol tipo $A$ quando o $\beta$-cetoéster é um anel de sete membros [7], Figura 8.

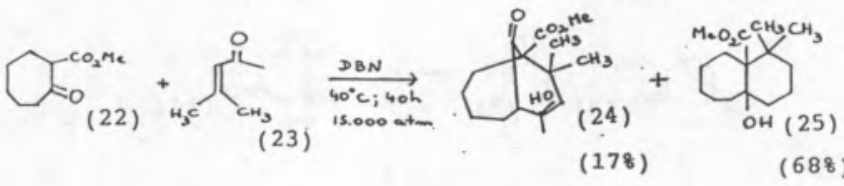

Figura 8

Ciclizaçâo sob pressão

Repare-se nos rendimentos significativamente diferentes da anelação de Robinson dos dois aductos de Michael representados a seguir [8], Figura 9.
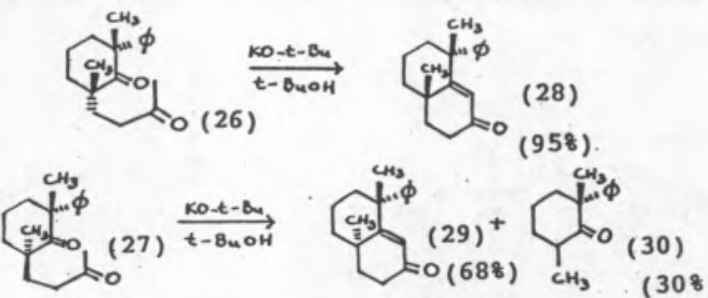

Figura 9

Anelaçâo de Robinson de (26) e (27)

A formação da monocetona (30) a partir de (27) pode ser racionalizada se se atender a uma das conformações do aducto, (31), Figura 10,

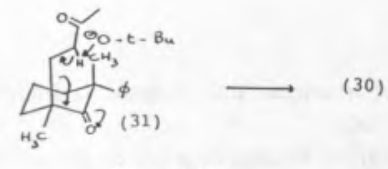

Figura 10

Uma das conformaçōes de (27) ou seja, se a cadeia lateral de butanona se encontrar em posição axial, há grande probabilidade de se dar a reacção retógrada [8]; o mesmo não acontece com (26), (Figura 9), pois a conformação correspondente com a cadeia de butanona em posição axial é muito pouco favorecida, Figura 11.
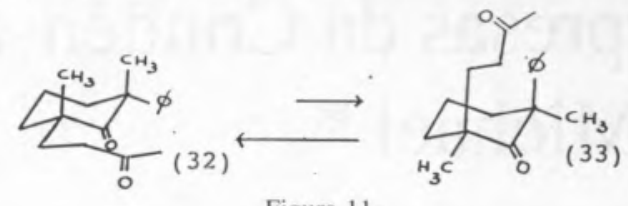

Figura 11

Conformações de (26)

Da reacção do 1-acetil-2-oxo-ciclohexano com a trans-3-penteno-2-ona, Figura 12,

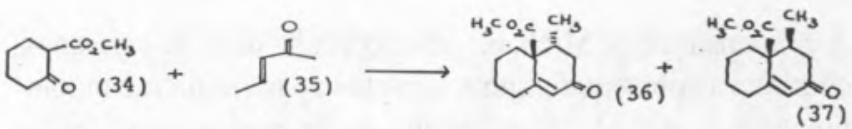

Figura 12

Anelação de Robinson de (34) com (35)

pode dizer-se que a obtenção exclusiva de um dos isómeros nunca foi conseguida. No entanto, a proporção relativa de (37)/(38) é de 3:1 quando a reacção decorre em presença de ter-amilato de potássio em álcool ter-amílico a $-15{ }^{\circ} \mathrm{C}$ e de 0,6:1 com metóxido de sódio em dimetilsulfóxido a $29^{\circ} \mathrm{C}$ [9].

Outra grande variação na proporção dos isómeros cis/trans é a que se verifica quando se faz reagir a 2-metil-ciclohexanona com a trans-3-penteno-2-ona [10], Figura 13,
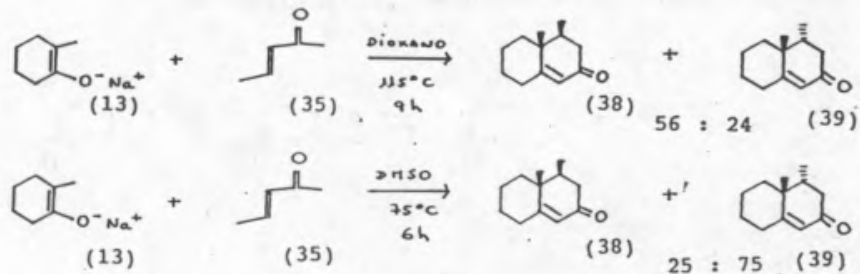

Figura 13

Reaçaão do enolato sódico de 2-metil-ciclohexanona com trans-3-penteno-2-ona em dioxano e dimetilsulfóxido

concluindo-se que o papel desempenhado pelo solvente neste tipo de reacção é deveras significativo.

Um caso particular muito importante da anelação de Robinson é a chamada reaç̧ão de Hajos-Parrish [11], Figura 14.

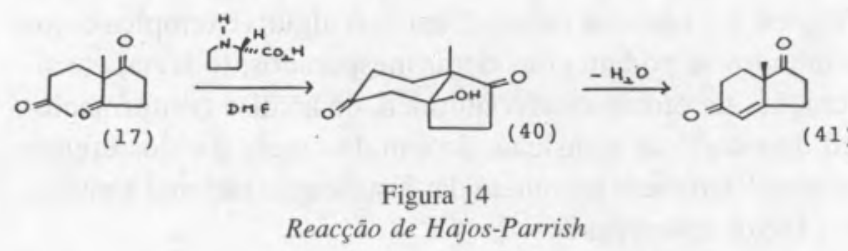

Repare-se que o tratamento do aducto de Michael (17) com um reagente opticamente activo, a (S)-(-)-prolina, conduz à formação de um só enantiómero do cetol e do produto de desidratação, com excessos enantioméricos de $93,4 \%$ e $87,7 \%$, respectivamente, sendo actualmente o mecanismo de catálise ainda motivo de controvérsia. 
Não deixa de ser curioso, no entanto, que a (S)-homoprolina induza a quiralidade oposta ao mesmo substracto em condições idênticas [12], Figura 15, com excesso enantiométrico de $58 \%$,

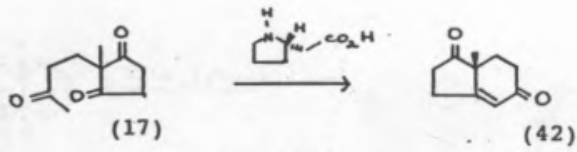

Figura 15

Reacção de Hajos-Parrish com (S)-homoprolina

e que $\mathrm{N}$-anilidas correspondentes a cada um dos aminoácidos induzam a quiralidade oposta [12] à induzida pelo aminoácido respectivo, Figura 16, com excessos enantioméricos de 15 a $25 \%$.
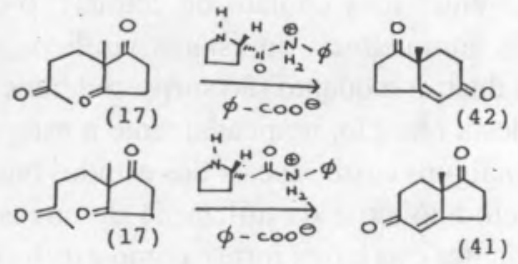

Figura 16

Reacção de Hajos-Parrish com as $\mathrm{N}$-anilidas da (S)-prolina e (S)-homoprolina

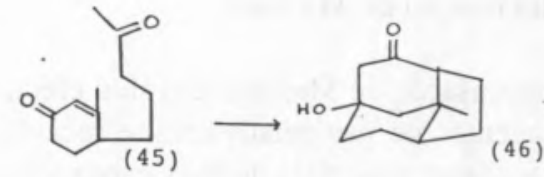

Figura 18 Condensaçẫo de Michael de (45)

só se podendo justificar a condensação aldólica posterior na fusão cis dos dois anéis.

Não se conseguiu estereoselecitividade por tratamento dos substractos (47) e (48) com ter-butóxido de potássio em álcool ter-butílico; no entanto, verificou-se posteriormente que os respectivos quelatos metálicos conduzem à formação dos isómeros trans [15], Figura 19,

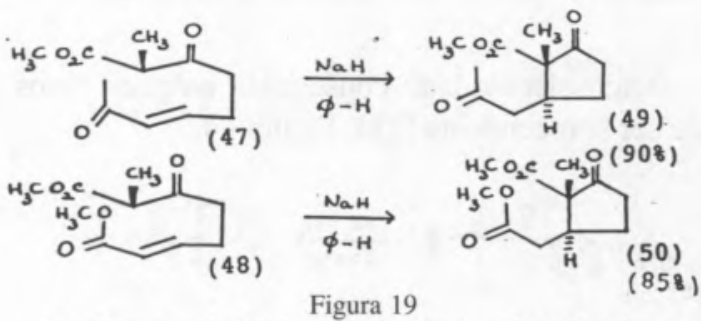

Condensação de Michael de substractos de cadeia linear

o que é explicável em termos da conformação preferida nos respectivos estados de transição [15], Figura 20.

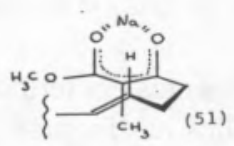

Figura 20

Estado de transiçâo preferido pelo substracto (48)

Verificou-se estereoselectividade semelhante para o substracto (52) da Figura 21, em que o seu tratamento isolado com (R) e (S)-1-feniletilamina conduziu à formação dos dois enantiómeros de fusão trans [16],

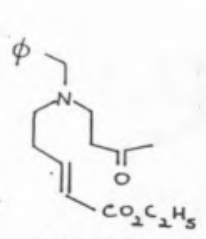

(52)

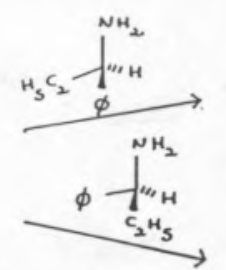

Figura 21

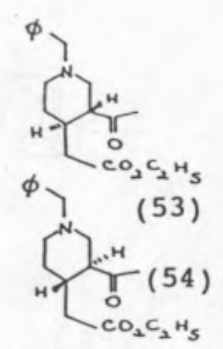

Condensaçāo de Michael do substracto (52)

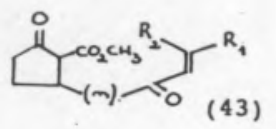

(43)

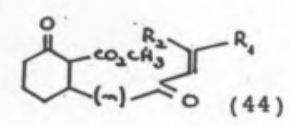

$\mathrm{R}_{1}, \mathrm{R}_{2}=\mathrm{H}, \mathrm{CH}_{3}$

Figura 17

Condensação de Michael de substractos contendo a dupla ligação enólica num anel

Do mesmo modo, a condensação de Michael do substracto (45) resultou em (46) [14], Figura 18, o que é novamente racionalizável em termos da conformação preferida pelo substracto [16] nos respectivos estados de transição, Figura 22.

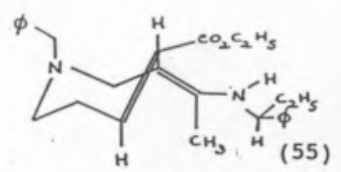

Figura 22

Estado de transição provável que leva à formaçâo do isómero trans 


\section{Dupla condensação de Michael}

A dupla condensação de Michael tem sido efectuada recorrendo a reagentes de uso relativamente recente, como os sililantes e a diisopropilamida de lítio, capazes de promover a formação de iões dienolato. O impedimento estereoquímico pode ser um factor limitativo desta reacção [17]. Figura 23,

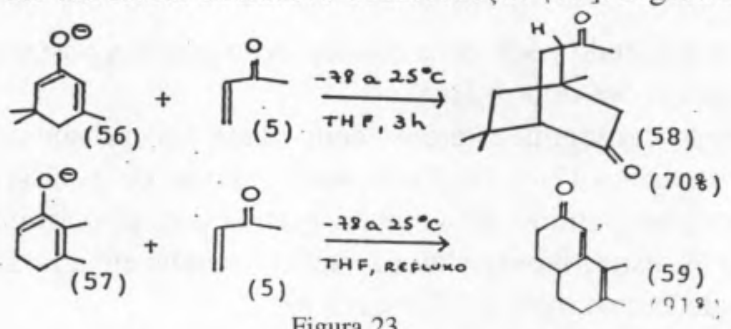

Figura 23

Dupla condensação de (56) e anelação de Robinson de (57)

mas a estereoselectividade conseguida nalguns casos não deixa de ser surpeendente [18], Figura 24,

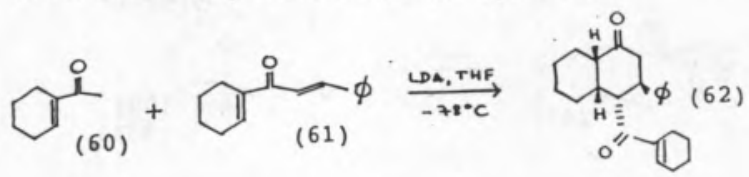

Figura 24

Dupla condensação de Michael de (60) com (61)

principalmente se se tiver em conta que a reacção de Diels-Alder do substracto (61) com o éter enólico sililado de (60) resultou na formação de (62) e de mais dois outros estereoisómeros [18].

Outros casos surpreendentes em termos de estereoselectividade são os apresentados nas Figuras 25 [19] e 26 [20],

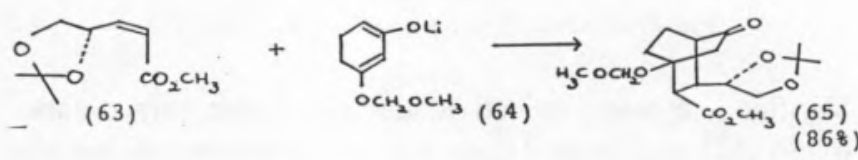

Figura 25

Dupla condensação de Michael de (63) e (64)

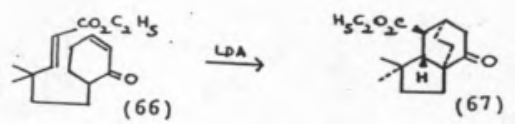

Figura 26

Dupla condensaçẩo de Michael de (66) aos quais é atribuído ao catião lítio um papel relevante nos estados de transição.

Também há exemplos de estereoselectividade significativa no uso de derivados sililados [21], Figura 27.

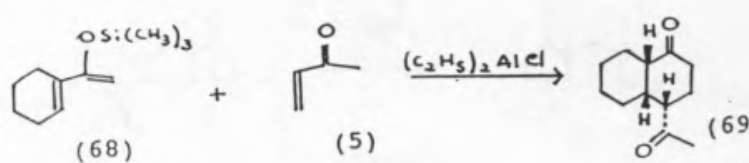

Figura 27

Dupla condensação de Michael de (68) com (5)

\section{Conclusões}

Neste trabalho recorreu-se a um número muito limitado de exemplos de condensação de Michael, - só foram analisadas reacções entre iões enolato de cetonas, $\beta$-dicetonas e $\beta$-cetoésteres com cetonas ou ésteres vinílicos, - mas eles bastam para ilustrar o quanto são surpreendentes muitos dos resultados desta reacção, nomeadamente a estereoselectividade obtida nalguns casos, apesar dos estudos recentes sobre equilíbrio ceto-enólico e da utilização de novos reagentes, como os sililantes e as bases fortes, como a diisopropilamida de lítio, capaz de promover a formação de iões dienolato.

\section{Referências}

[1] Adam, R. et all, Organic Reactions, vol. X. J. Wiley and Sons, 179-555, 1959.

[2] Jung, M., Tetrahedron, 32, 3, 1976.

[3] Gawley, R., Synthesis, 777, 1976.

[4] Marshall, J.; Fanta, W., J. Org. Chem., 29, 2501, 1964.

[5] Deslongschamps, P., Stereoelectronic Effects in Organic Chemistry, vol. I, Pergamon Press, 1983.

[6] Hajos, Z.; Parrish, D., J. Org. Chem., 39(12), 1612, 1974.

[7] Dauben, W.; Bunce, R., J. Org. Chem., 48, 4642, 1983.

[8] Ireland, R.; Kierstead, R., J. Org. Chem., 31, 2543, 1966.

[9] Marshall, J.; Warne, T., J. Org. Chem., 36, 178, 1971.

[10] Kikuchi, M.; Yoshikhoshi, A., Bull. Chem. Soc. Jap., 54(11), 3420, 1981.

[11] Hajos, Z.; Parrish, D., J. Org. Chem., 39(12), 1615, 1974.

[12] Eschenmoser, A. et all, Helv. Chim. Acta, 61(8), 1978.

[13] Berthiaume, G.; Lavallée, J.; Deslongschamps, P., Tetrahedron Lett., 27(45), 5451, 1986.

[14] Johnson, W.; Shulman, S.; Williamson, K., Pappo, R., J. Org. Chem., 27, 2015, 1962.

[15] Stork, G.; Winkler, J.; Saccomano, N., Tetrahedron Lett., 24(5), 465, 1983.

[16] Hirai, Y. et all, J. Am. Chem. Soc., 110, 958, 1998.

[17] White, K.; Reusch, W., Tetrahedron, 34, 2439, 1978.

[18] Richter, F.; Otto, H., Tetrahedron Lett., 26(36), 4351, 1985.

[19] Nagaoka, H. et all, Tetrahedron Lett., 28(52), 6641, 1987.

[20] Ihara, M. et all, J. Chem. Soc. Perkin-Trans I, 1155,1988.

[21] Hagiwara, H. et all, J. Chem. Soc. Chem. Comm., 1333,1987. 


\section{Quimicando}

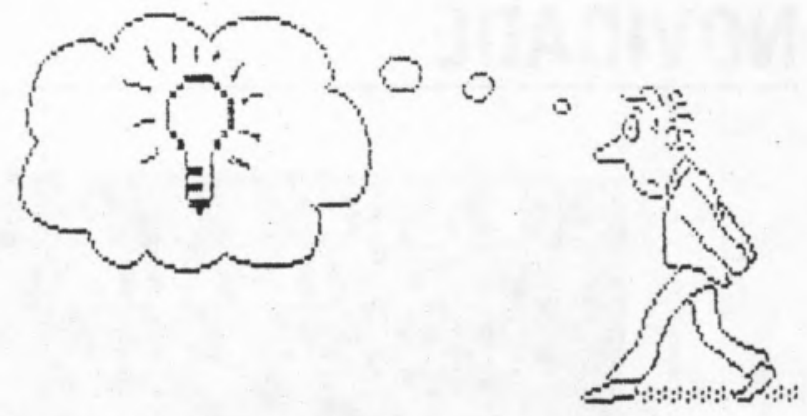

A química pode ser entendida por alguns como uma brincadeira feita de cor, artifícios, explosões. Para outros, é um labirinto do qual não conseguem sair. Outros ainda associam-na a cabelos em pé, pessoas meio doidas!

Mas a Química é essencialmente uma Ciência muito importante e indispensável para todos nós. O espantoso mundo da Química, colorido e divertido, engloba, de entre muitos outros, um país igualmente interessante que todos decerto gostarão de conhecer - O PAÍS DAS REACÇÕES QUIIMICAS.

Que tal fazermos uma pequena viagem a este país?

Ao caminharmos pelas suas ruas fantásticas, apercebemo-nos que os seus habitantes - os reagentes - passeiam com os seus filhos - os produtos de reacção.

Há no entanto factos curiosos: os filhos, na maior parte das vezes, não têm quaisquer semelhanças com os seus pais. Por vezes, entre os cidadãos observam-se mudanças várias de aspecto. Para se evitar que hajam perturbações incontroláveis existem ruas seleccionadas - a Rua dos Ácidos, a Rua das Bases (onde se vê que a Sra. Fenolftaleína, ilustre senhora que distingue todos os moradores desta rua, estejam eles onde estiverem, faz corar os vizinhos), a Rua dos Cristais (a mais rica e luxuosa deste país) e outras. Finalmente, tal como em todos os países, existe a Penitenciária, onde estão os cidadãos mais perigosos - os produtos tóxicos.

Outro aspecto do qual nos apercebemos imediatamente é o seguinte - todos andam bem agasalhados, evitando o contacto com a luz, com a água, pois podem sofrer transformações e seria muito aborrecido se tivessem de mudar de rua!

É este um país rico, alegre, colorido, bonito, e que vale a pena visitar.

Se o quiserem conhecer, contactem a Quimicotecnia. Verão que vão gostar e não se arrependerão! Até breve!

Ângela Ribeiro 


\section{NOVIDADE}

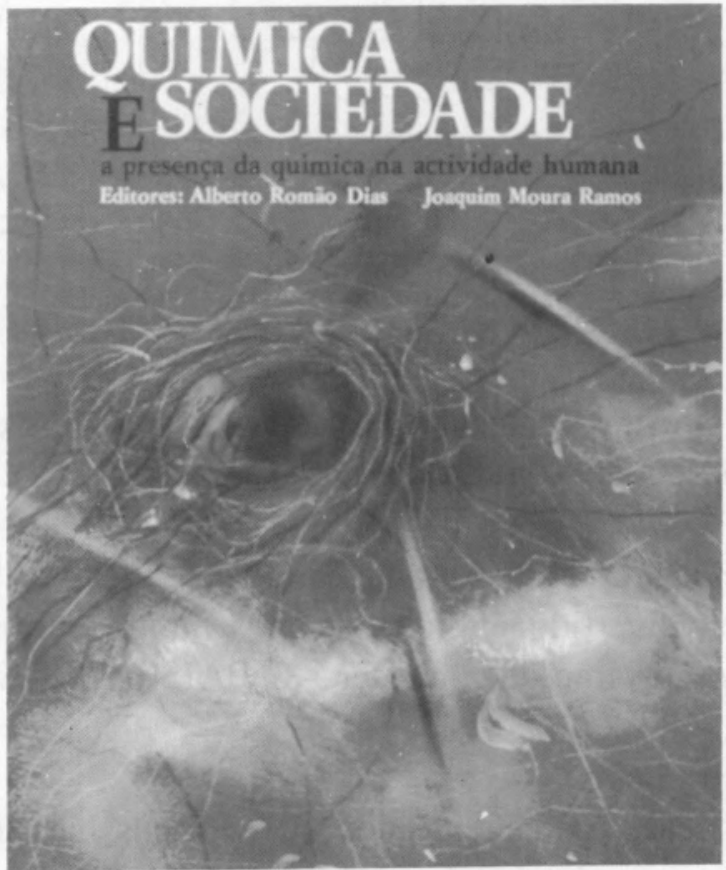

\section{Um livro \\ indispensável \\ para todos os}

interessados

no papel

da Química

na vida

da Sociedade

UMA

PUBLICAÇÃO

CONJUNTA

DA

SOCIEDADE PORTUGUESA DE QUIMICA

E

DA

LIVRARIA ESCOLAR EDITORA

EDITORES:

A. ROMÃO DIAS E J. MOURA RAMOS

COM O APOIO DA JNICT

\section{QUÍMICA E SOCIEDADE}

A PRESENÇA DA QUIMICA NA ACTIVIDADE HUMANA

ÍNDICE

A Evolução Química no Espaço e no Sistema Solar e - Problema da Origem da Vida

Joaquim J. Moura Ramos

A Evolução Química na Terra e o Problema da Origem da Vida

Hernâni Maia

Moléculas da Vida Ana Lobo

Química e Saúde Eduarda Rosa e Fátima Norberto

\section{Química e Pré-História: A Datação pelo \\ Radiocarbono \\ J.M. Peixoto Cabral}

A VENDA

NAS

LIVRARIAS

$1800 \$ 00$

Fotografia: da Magia à Química-Física Eurico C. Melo

A Quimica na Arte Maria Alzira A. Ferreira

Química e o Aumento das Produções Agrícolas Joaquim Quelhas dos Santos

A Química e a Alimentação: A Química na Cozinha Vera F. Sá da Costa

Química; Crime; Sociedade António Pinho de Aguiar

NOME

MORADA

Sou sócio da SPQ e desejo receber um exemplar do livro QUímICA E SOCIEDADE para o que envio o cheque № 